\title{
Human Language Technology and communicative disabilities: Requirements and possibilities for the future
}

\author{
Marina B. Ruiter ${ }^{1}$, Toni C.M. Rietveld ${ }^{2}$, Catia Cucchiarini ${ }^{3}$, Emiel J. Krahmer ${ }^{4}$, Helmer Strik ${ }^{2}$ \\ ${ }^{1}$ Sint Maartenskliniek Research, Development \& Education, Nijmegen, Hengstdal 3, 6522 JV, Nijmegen, The \\ Netherlands, ${ }^{2}$ Radboud University, Dept. of Linguistics, Erasmusplein 1, 6525 HT Nijmegen, The Netherlands, \\ ${ }^{3}$ Nederlandse Taalunie, Lange Voorhout 19, 2501 HN The Hague, The Netherlands, ${ }^{4}$ Tilburg University, Dept. of \\ Communication and Information Sciences, P.O. Box 90153, 5000 LE Tilburg, The Netherlands. \\ E-mail: m.ruiter@maartenskliniek.nl, a.rietveld@let.ru.nl, ccucchiarini@taalunie.org, e.j.krahmer@uvt.nl, \\ w.strik@let.ru.nl
}

\begin{abstract}
For some years now, the Nederlandse Taalunie (Dutch Language Union) has been active in promoting the development of human language technology (HLT) applications for users of Dutch with communication disabilities. The reason is that HLT products and services may enable these users to improve their verbal autonomy and communication skills. We sought to identify a minimum common set of HLT resources that is required to develop tools for a wide range of communication disabilities. In order to reach this goal, we investigated the specific HLT needs of communicatively disabled people and related these needs to the underlying HLT software components. By analysing the availability and quality of these essential HLT resources, we were able to identify which of the crucial elements need further research and development to become usable for developing applications for communicatively disabled users of Dutch. The results obtained in the current survey can be used to inform policy institutions on how they can stimulate the development of HLT resources for this target group. In the current study results were obtained for Dutch, but a similar approach can also be used for other languages.
\end{abstract}

\section{Introduction}

Dutch language users with communication disabilities are hampered in their communicative efficacy and efficiency. That is, without other people helping them, they may not be able to get their message across adequately and fluently in Dutch. Similarly, it may be difficult for them to understand what other people tell them or put in writing. HLT may help to improve their functional communication skills, because HLT may allow them to restore or compensate their communication disorder.

An example on aphasia may illustrate this. Aphasia is a neurological language disorder that can result from a stroke. The frequency of aphasics among stroke patients typically ranges from 21 to $38 \%$ (e.g., Engelter et al., 2006). Thus, at least 21 out of the 100 persons suffering a stroke develop aphasia in the sub-acute phase. Of these 21 persons, typically 4 pass away, 4 recover during the first months post-onset, and 4 remain aphasic. The outcome of the remaining 9 persons cannot be predicted accurately (Niewold, 2006). Aphasia can manifest itself in all language faculties, such as spoken language production. There are strong indications that intensive training can improve aphasics' functional communication skills (Bhogal, Teasell, Foley, \& Speechley, 2003). Emerging HLT technologies may for example be used to create virtual therapists that help aphasic speakers to train these skills (e.g., Cherney, Halper, Holland, \& Cole, 2008).

Being far from exhaustive, we provide two other examples that illustrate how HLT enables communicatively disabled people to improve their communication skills. Within the Speech Algorithms for Clinical and Educational Applications (SPACE) project, speech recognition and synthesis technology were used to develop an automated reading tutor which allows (dyslectic) children to train their oral reading performance (e.g., Duchateau et al., 2009). Technology that assesses the intelligibility of dysarthric speech was created as well (e.g., Van Nuffelen, Middag, De Bodt, \& Martens, 2009). ${ }^{1}$

\subsection{Human Language Technology and communication disabilities}

The Dutch Language Union is a Dutch-Flemish intergovernmental organisation that aims at creating the right conditions in which speakers of Dutch can use this language in as many communicative settings as possible. The leading principle of the efforts of the Dutch Language Union is to achieve this for all users of Dutch, also for those with communication disabilities. Against this background, the Dutch Language Union has been exploring the possibilities offered by HLT products and services to improve the verbal autonomy of communicatively disabled users of Dutch.

A first initiative of the Dutch Language Union to investigate the potential of HLT for people with communication disabilities in the Netherlands and Flanders was the survey carried out by Rietveld and Stolte (2005). The authors interviewed experts from a variety of disciplines covering the various groups of people with communication disabilities and experts from the HLT sector (e.g., health care providers and providers of augmentative and alternative communication tools). With their responses, it was determined: (a) what HLT tools are currently available for people with communication disabilities, (b) what experiences the users have with these tools (in terms of quality and applicability), and (c) whether the HLT market could help to meet the needs that were not yet fulfilled. In 2005, Rietveld and Stolte

\footnotetext{
${ }^{1}$ For detailed information, see the SPACE home page: http://www.esat.kuleuven.be/psi/spraak/projects/SPACE/ .
} 
concluded that although people with communication disorders in the Netherlands and Flanders appeared to have urgent needs that could be fulfilled by HLT applications, these needs were not met at that time. Although several HLT applications have been developed over the last five years, anno 2010, the HLT needs of communicatively disabled users of Dutch are not yet completely fulfilled. At least in part, this seems to be due to the diversity of the disorders underlying the communication disabilities, which makes it difficult to develop products that can be used by relatively large numbers of communicatively disabled people.

\subsection{A new initiative to investigate requirements and possibilities for the future}

The present study forms a continuation of the 2005 study conducted by Rietveld and Stolte. By investigating the specific needs of communicatively disabled people and relating these needs to the HLT software components underlying the applications called for, we sought to identify a minimum common set of HLT resources that is required to develop as many tools as possible for the wide range of communication disabilities. This research aim can be subdivided into several sub-questions:

(a) Which HLT applications should be developed for users of Dutch with communication disabilities in order to meet their needs?

(b) Which HLT software components underlie the applications that are most needed by users of Dutch with communication disabilities?

(c) Are the essential HLT resources available, and if so - does the quality suffice?

(d) If the quality of an essential HLT resource does not suffice, what is the research effort necessary to improve its quality?

\section{Methods}

As discussed above, the diversity of the disorders underlying the communication disabilities and the various HLT needs make it difficult to develop products that can be used by large groups (Rietveld \& Stolte, 2005). In order to investigate whether these difficulties can be overcome, at least for the greater part, the present study followed an approach that was similar to the one adopted in preparation of the Dutch-Flemish HLT programme STEVIN (a Dutch acronym for Essential Speech and Language Technology Resources). This research and industry stimulation programme started in 2004 under the auspices of the Dutch Language Union and is funded by the Dutch and Flemish governments. An important element of the STEVIN programme was the definition of the Basic Language Resources Kit for Dutch (BLARK; Daelemans \& Strik, 2002). The BLARK concept (Krauwer, 1998) was also used to specify a basic language resources kit for other languages, for example Arabic (e.g., Maegaard, Krauwer, \& Choukri, 2009) and Swedish (Elenius, Forsbom, \& Megyesi, 2006). In the BLARK, the basic software components that are essential for developing HLT applications were specified. By analysing the availability and quality of the various components, it could be determined which essential elements were missing or did not meet the requirements. As a consequence, it was possible to establish which HLT software components have to be developed with priority. Relevant for the present survey is that several matrices were used in defining the BLARK for Dutch: A distinction was made between applications, modules, and data. As will be discussed below, a similar approach was used in the present study.

\subsection{Matrices}

A stepping-stone to the present survey was a round table conference that was organised by the Dutch Language Union on September 28, 2007 (Cucchiarini, 2008). Experts from the HLT sector and from the clinical field participated. At this conference, a working group of experts was formed - the MATRIX working group - who discussed which matrices could be used in drawing up the HLT resources that are required to develop applications for communicatively disabled users of Dutch (Cucchiarini et al., 2008; Strik, 2008). During the survey, the matrices produced by the MATRIX working group were adapted as a result of feedback from the clinical field. The following matrices were used to specify the HLT needs as brought forward during the round table conference and in the interviews with 20 clinical experts:

- Applications x conversions: What conversions between communication modalities are needed to develop an HLT-based tool?

- Conversions x modules: What HLT software modules underlie each conversion?

In the BLARK, the types of data needed to build, improve, or evaluate HLT software modules were defined as well. In the present study, however, we did not specify the data, because a separate database will be required for each (sub)group of communicatively disabled users of Dutch. This is related to the fact that the variability between these users is considerable. Even within a particular subgroup of communicatively disabled users of Dutch (e.g., within the group of dysarthric speakers) speech characteristics may vary to a great extent.

\subsubsection{Applications}

On the first axis of the matrices, we described the HLT applications that users of Dutch with communicative disabilities had indicated to be in need of. The following four dimensions were distinguished:

- The purpose of the application: diagnosis, monitoring, restoration or compensation therapy, or augmentative and alternative communication (AAC).

- The communication function which has to be fulfilled: reading, writing, listening, or speaking.

- The target group, as defined by the underlying impairment: mental/cognitive (e.g., aphasia), sensory (e.g., blind), voice and speech (e.g., 
dysarthria), and motor (e.g., Repetitive Strain Injury).

- Age: children and youngsters (up to 18 years), adults (18 to 65 years), and elderly people (65 years or older). HLT demands may differ depending on the age of the users. For instance, automatic speech recognition of children needs specific adjustment.

\subsubsection{Conversions}

In order to be able to specify for each and every application the underlying HLT software components, the applications were considered as conversions between the following five communication modalities:

1) Spoken language

2) Written language

3) Non-verbal: images, animations, symbols, gestures, or agents

4) Tactile: Braille or 3D-images (with relief)

5) Concepts: data, pictures, or key words, such as stock market reports printed in newspapers.

To make clear what the relation is between conversions of modalities and (classes of) technologies, some examples are given below:

$1 \rightarrow 2$ : speech recognition

$2 \rightarrow 1$ : speech synthesis

$2 \rightarrow 2$ : text modification, summarizing, indexing, etc.

$2 \rightarrow 3$ : from text to virtual talking heads, agents, gestures, etc.

\subsubsection{Modules}

On the third axis of the matrices, we specified the HLT software modules underlying the conversions between communication modalities that communicatively disabled people need to use to get their messages across and/or to derive the communicative intention of other people. Since not all conversions could be realised with the BLARK modules (Daelemans \& Strik, 2002), the following additional modules were defined:

- Text-to-gestures

- Recognition of gestures

- Text-to-symbols

- Recognition of symbols

- Generation of facial expression and articulation on talking heads

- Recognition of pathological speech

\subsection{Procedure}

For each and every HLT need that was brought forward during the round table conference or in the interviews with the clinical experts, the underlying conversions were established (an example is given in Table 1). As Table 1 illustrates, several conversions may be needed to develop a particular HLT application. In total, 97 conversions are needed to develop the 65 HLT applications that users of Dutch with communication disabilities seem to require.

\begin{tabular}{|c|c|}
\hline \multicolumn{2}{|c|}{ Requested HLT application: Writing Aid } \\
\hline \multicolumn{2}{|c|}{$\begin{array}{l}\text { Description: People with mild aphasia or dysortho- } \\
\text { graphia could benefit from an application that they can } \\
\text { use when writing a letter, paper, or e-mail. It should } \\
\text { provide: word prediction, sentence prediction, spell and } \\
\text { grammar checker tools, and advice on which register to } \\
\text { use (e.g., formal or informal). It should also include } \\
\text { speech synthesis, because it allows users to monitor } \\
\text { and correct their own writing. Lastly, users should be } \\
\text { able to produce a grammatically well-formed written } \\
\text { sentence by putting symbols into a sequence. }\end{array}$} \\
\hline (1) Application & $\begin{array}{l}\text { - Purpose: AAC } \\
\text { - Communication function: writing } \\
\text { - } \underline{\text { Target group: mental/ cognitive }} \\
\text { (aphasia, dysorthographia) } \\
\text { - } \text { Age: all }\end{array}$ \\
\hline (2) Conversions & \\
\hline
\end{tabular}

Table 1: Example of a requested HLT application (for explanation see text).

\subsubsection{Quantitative analysis of conversions}

The quantitative analysis of the 97 conversions derived with the procedure described above, yielded a hierarchy of conversions arranged by descending order of occurrence. In the current study, only the five most frequently occurring conversions were used for further analysis (cf., Table 2). Table 2 for example shows that $32 \%$ of the 97 conversions consisted of speech synthesis. One could argue that the conversions speech synthesis and speech recognition do not need to be developed for communicatively disabled users specifically as these conversions are already (at least partially) available for healthy users of Dutch. In arguing against this statement, it is important to emphasize that these conversions need specific adjustments in order to be employed in applications for communicatively disabled users. For example, due to the error-prone character of aphasic speech (e.g., substitutions of words, sounds, and ungrammatical utterances), the already available speech recognition resources do not suffice to recognise the speech of aphasic speakers.

\begin{tabular}{|c|l|c|}
\hline \multicolumn{2}{|l|}{ Conversion } & Frequency (in \%) \\
\hline $2 \rightarrow 1$ & Speech synthesis & 32 \\
\hline $1 \rightarrow 2$ & Speech recognition & 26 \\
\hline $2 \rightarrow 2$ & Text modification & 12 \\
\hline $3 \rightarrow 1$ & Non-verbal to speech & 8 \\
\hline $2 \rightarrow 3$ & Text to non-verbal & 7 \\
\hline
\end{tabular}

Table 2: Hierarchy of the five most frequently occurring conversions $(N=97)$. 


\subsubsection{Achieving consensus}

The MATRIX working group achieved consensus on the software modules needed to realise the essential conversions.

Secondly, the MATRIX working group agreed on the availability and quality of the software modules underlying the five most frequently occurring conversions An HLT resource was considered available when it was either commercially or experimentally accessible (indicated with $\mathrm{C}$ and $\mathrm{E}$ respectively in Table 3). Quality was rated at a 4-point rating scale: $\operatorname{good}(\mathrm{G})$, sufficient $(\mathrm{S})$, insufficient (I), or poor (P). In the present study, only the HLT software resources rated as sufficient or good were considered to be of adequate quality in order to be beneficial to communicatively disabled people.

Lastly, the MATRIX working group made an estimation of the research effort needed to develop or improve HLT software modules whose quality appeared not to be up to the standards required. Only if a relatively small research effort was expected to be needed in order to improve quality or to make it more suitable for a specific application, was the complexity of a specific module rated as low (L). Conversely, whenever substantial research effort was anticipated to improve quality, the complexity was rated as high $(\mathrm{H})$. The label average (A) was given if an average research effort was anticipated.

\section{Results}

In this section, we present the main results relating to the sub-questions formulated in the Introduction.

\subsection{HLT applications required}

Although inventorying the needs of people with communicative disabilities constituted the immediate goal of the present survey, it was not its ultimate goal. The ultimate goal of the current survey was to define the availability and quality of a minimum set of HLT resources that is required to develop as many tools as possible for the wide range of communication disabilities. For this reason, we do not provide a complete overview of the HLT applications required $(N=65)$, but limit ourselves to providing some examples of useful applications in Section $4 .^{2}$

\subsection{Underlying HLT software components}

Table 3 presents the essential (indicated with X) and optional (indicated with parenthesis) modules underlying the five most frequently occurring conversions. For example, for the conversion speech synthesis, the following modules are essential: grapheme-to- phoneme conversion, text pre-processing, lemmatising \& morphological analysis, morphosyntactic disambiguation, syntactic analysis, prosody generation, and complete speech synthesis. The module semantic \& pragmatic analysis is optional.

\footnotetext{
${ }^{2}$ Readers wishing to obtain the entire data set should contact the first author.
}

\subsection{Availability and quality of the modules}

As Table 3 illustrates, the availability and quality of the essential modules varies considerably. Some modules are both available and of sufficient quality. This holds for example for the HLT module lemmatising \& morphological analysis. However, not all minimally required modules are available and good enough to be employed for developing applications for communicatively disabled users of Dutch. The module text generation is neither commercially nor experimentally available. Consequently, its quality is rated as poor. It seems paradoxical that, although language \& dialect identification is not available, its quality is rated as sufficient. This is due to the fact that promising results have been obtained in scientific research; however, an experimental version of this module is not available yet.

\subsection{Research effort needed to improve quality}

For the HLT resources lacking sufficient quality, the anticipated research effort is given in Table 3. For example, in order to improve the quality of the module recognition pathological speech a substantial research effort is needed. This is due to the considerable variability in speech production between and within communicatively disabled users of Dutch.

\section{Conclusions}

The most important question of the current survey is which HLT resources need to be developed or improved first in order to fulfil the needs of communicatively disabled users of Dutch best. As discussed in the Introduction, the criterion of multiple-usability was used in the present survey. Put differently, we sought to identify a minimum set of HLT resources that is required to develop as many tools as possible for the wide range of communication disabilities. It is however important to emphasize that other criteria can be used to answer the question presented above, such as prevalence and severity of the communication disorder. In addition, feasibility can be used as a criterion, as is illustrated by the survey of the Flemish Government department EWI (Dutch acronym for Economics, Science, and Innovation; Kenis, 2009). In the present survey, however, we did not use feasibility as a criterion because the development and improvement of HLT resources is directly related to the amount of research budget available. For that reason, we will restrict ourselves to summarising the availability and quality of the essential HLT resources underlying the five most frequently occurring conversions. ${ }^{3}$ In the following sections, we will summarise the research effort anticipated to improve the quality of the HLT resources as well.

\footnotetext{
${ }^{3}$ For clarity's sake, the availability and quality of the optional modules is not discussed in this section (for information about these modules, see Table 3).
} 


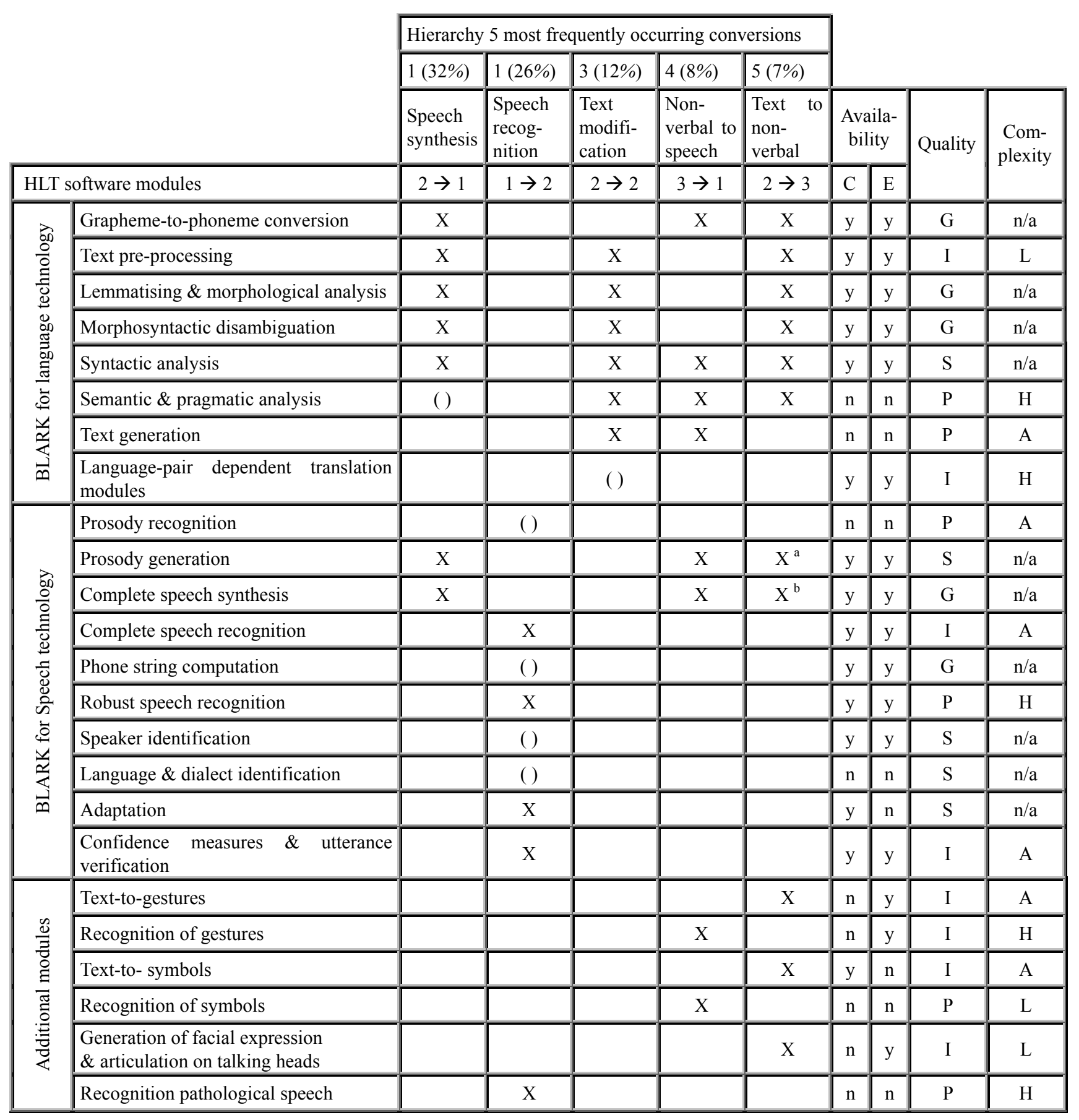

Table 3: Essential (X) and optional ( ) HLT resources underlying the five most frequently occurring conversions, including availability of each software module $(\mathrm{C}=$ commercially, $\mathrm{E}=$ experimentally accessible $)$, its quality $(\mathrm{G}=$ good, $\mathrm{S}=$ sufficient, $\mathrm{I}=$ insufficient, or $\mathrm{P}=$ poor), as well as its complexity (i.e., the research effort anticipated to develop or improve the HLT software module: $\mathrm{L}=$ low, $\mathrm{A}=$ average, or $\mathrm{H}=$ high).

${ }^{\mathrm{a}, \mathrm{b}}$ Prosody generation and complete speech synthesis are necessary for converting text to NmG or SMOG (Dutch acronyms for spoken language supported by gestures).

\subsection{Concluding remarks on speech synthesis}

Speech synthesis is the most frequently occurring conversion underlying the tools needed by communicatively disabled users of Dutch. All seven essential modules are available and - except for text pre-processing - have sufficient or good quality (cf.,
Table 3). A relatively small research effort is anticipated to improve the quality of the latter module. Thus, by improving the quality of only one module, applications based on speech synthesis can be developed. Table 4 gives an example of a speech synthesis-based application that communicatively disabled appear to find useful. 


\begin{tabular}{|c|c|}
\hline \multicolumn{2}{|c|}{ Requested HLT application: Speech conversion } \\
\hline \multicolumn{2}{|c|}{$\begin{array}{l}\text { Description: personalized synthetic speech is created } \\
\text { on speaker's own voice recordings at an early stage of } \\
\text { their disease. }\end{array}$} \\
\hline (1) Application & $\begin{array}{l}\text { - Purpose: AAC } \\
\text { - } \text { Communication function: } \\
\text { speaking } \\
\text { - Target group: voice \& speech (e.g., } \\
\text { progressive diseases such as } \\
\text { Amyotrophic Lateral Sclerosis or } \\
\text { larynx extirpation) } \\
\text { - Age: adults and elderly }\end{array}$ \\
\hline (2) Conversion & $-1 \rightarrow 1$ \\
\hline
\end{tabular}

Table 4: Example of a requested HLT application based on speech synthesis

\subsection{Concluding remarks on speech recognition}

Speech recognition is the second most frequently occurring conversion underlying the tools needed by communicatively disabled users of Dutch. As Table 3 illustrates, many HLT resources need to be developed or improved in order to enable communicatively disables users of Dutch to benefit from speech recognition. Four out of the five essential HLT modules are available. However, only one (i.e., adaptation) is of sufficient quality. The research effort needed to improve the quality of the remaining four modules ranges from average (complete speech recognition and confidence measures \& utterance verification) to high (robust speech recognition and recognition pathological speech). As indicated before, a substantial research effort is needed in order to develop the module recognition pathological speech. This is due to the considerable between and within-subject variability in pathological speech production. An example of an HLT that is based on speech recognition is given in Table 5 .

\begin{tabular}{|c|c|}
\hline \multicolumn{2}{|c|}{ Requested HLT application: Conversation analysis } \\
\hline \multicolumn{2}{|c|}{$\begin{array}{l}\text { Description: the conversation } \\
\text { communicatively disabled speaker and their } \\
\text { conversation partners should be transcribed } \\
\text { automatically. It should be possible to analyse the } \\
\text { language (e.g., syntax, pragmatics) or speech } \\
\text { characteristics (e.g., intonation, speech rate) of the } \\
\text { speech sample as well. }\end{array}$} \\
\hline (1) Application & $\begin{array}{l}\text { - Purpose: diagnosis, therapy } \\
\text { - Commun. function: speaking } \\
\text { - Target group: mental/cognition } \\
\text { (e.g., aphasia), voice and speech } \\
\text { (e.g., stuttering), motor (e.g., } \\
\text { verbal apraxia) } \\
\text { - Age: all }\end{array}$ \\
\hline (2) Conversion & $-1 \rightarrow 2$ \\
\hline
\end{tabular}

Table 5: Example of a requested HLT application based on speech recognition

\subsection{Concluding remarks on text modification}

Four out of the six HLT modules necessary to execute text modification are available. Except for text pre-processing, all available modules are of sufficient or good quality. As indicated in Paragraph 4.1., a small research effort is needed to improve text pre-processing. The modules semantic \& pragmatic analysis and text generation are also essential for text modification; however, none of these two modules is available yet. The complexity of these modules is high and average respectively. An illustration of an application that - in part - is based on text modification is given in Table 6 .

\begin{tabular}{|c|c|}
\hline \multicolumn{2}{|c|}{ Requested HLT application: Summarising } \\
\hline \multicolumn{2}{|c|}{$\begin{array}{l}\text { Description: the application should automatically } \\
\text { summarise texts in spoken or written form. }\end{array}$} \\
\hline (1) Application & $\begin{array}{l}\text { - Purpose: AAC } \\
\text { - Communication function: reading } \\
\text { - } \text { Target group: mental/cognition } \\
\text { (e.g., dyslexia, aphasia, and mental } \\
\text { retardation). } \\
\text { - Age: all }\end{array}$ \\
\hline (2) Conversions & $\begin{array}{l}-2 \rightarrow 2 \\
-1 \rightarrow 2\end{array}$ \\
\hline
\end{tabular}

Table 6: Example of a requested HLT application based on text modification

\subsection{Concluding remarks on non-verbal to speech}

Five out of the eight HLT modules essential to convert images, animations, symbols, gestures, or agents (i.e., non-verbal) into speech are available. Except for recognition of gestures, all available modules are of sufficient or good quality. A large research effort is needed to improve recognition of gestures. Semantic \& pragmatic analysis, text generation, and symbol recognition are essential as well in this conversion; however, not accessible yet. The research efforts needed to improve these modules varies from low (symbol recognition), average (text generation), to high (semantic \& pragmatic analysis). Table 7 illustrates an HLT application that is based on non-verbal to speech.

\begin{tabular}{|c|c|}
\hline \multicolumn{2}{|c|}{ Requested HLT application: Pictogram writing aid } \\
\hline \multicolumn{2}{|c|}{$\begin{array}{l}\text { Description: the application should automatically } \\
\text { generate a grammatically well-formed sentence based } \\
\text { on the pictograms selected and sequenced. }\end{array}$} \\
\hline (1) Application & $\begin{array}{l}\text { - } \text { Purpose: AAC } \\
\text { - Communication function: writing } \\
\text { - } \text { Target group: mental/cognition } \\
\text { (e.g., dysorthographia, aphasia, } \\
\text { and mental retardation). } \\
\text { - Age: all }\end{array}$ \\
\hline (2) Conversion & $-3 \rightarrow 2$ \\
\hline
\end{tabular}

Table 7: Example of a requested HLT application based on non-verbal to speech 


\subsection{Concluding remarks on text to non-verbal}

Ten out of the eleven HLT modules that are necessary to convert text into images, animations, symbols, gestures, or agents (i.e., non-verbal) are available. However, only six out of these 10 modules are of sufficient quality. The research efforts needed to improve the quality of the modules that do not meet the requirements yet ranges from low (text pre-processing and generation of facial expression \& articulation on talking heads), average (text-to-gestures and text-to-symbols), to high (semantic \& pragmatic analysis) Table 8 illustrates an HLT application that in part - is based on non-verbal to speech.

Requested HLT application: Sign language translator Description: Deaf and hard of hearing people do not always comprehend written language well enough to understand what others put in writing or tell them. For this reason, the application should automatically convert spoken or written language into sign language.

\begin{tabular}{|l|l|}
\hline (1) Application & - Purpose: therapy, AAC \\
& - Communication function: reading \\
& - and listening \\
& Target group: sensory (e.g., deaf \\
& and hard of hearing). \\
\hline (2) Conversions & $-1 \rightarrow 3$ \\
& $-2 \rightarrow 3$ \\
\hline
\end{tabular}

Table 8: Example of a requested HLT application based on text to non-verbal

\subsection{Final remarks}

After drawing the conclusions presented in the preceding sections, we would like to make a final comment. The question which HLT resources need to be developed or improved first in order to fulfil the needs of communicatively disabled users of Dutch best, is an important one. However, we are well aware that the answer is more difficult than the question itself. In part this is due to the fact that several criteria can be used in providing an answer. Although multipleusability was used as a criterion in this study, we sought to present the results in such a way that other criteria could also be used in analysing the results obtained. Accordingly, these results can be used to inform policy institutions on how they can stimulate the development of HLT resources for the group of communicatively disabled users. In the current study results were obtained for Dutch, but a similar approach can also be used for other languages.

\section{Acknowledgements}

We are indebted to the (other) members of the MATRIX working group (Dirk Lembrechts, Hugo Van hamme, Lilian Beijer, and Vincent de Jong), all interviewees and participants of the round table conference of September 28, 2007 (too many to name in person) as well as Antal van den Bosch, Onno Crasborn, Inge de Mönnink, Bart Noë, Arthur Dirksen, Michel Boekestein, Remco van Veenendaal, Loes Theunissen, and Marie Pruyn for their valuable contribution to the work presented in this paper.

\section{References}

Bhogal, S.K., Teasell, R.W., Foley, N.C., \& Speechley, M.R. (2003). Rehabilitation of aphasia: more is better. Topics in Stroke Rehabilitation, 10, 66-76.

Cherney, L. R., Halper, A. S., Holland, A. L. \& Cole, R. (2008). Computerized Script Training for Aphasia: Preliminary Results. American Journal of Speech-Language Pathology, 17, 19-34.

Cucchiarini, C. (2008). Een rondetafelconferentie over taal- en spraaktechnologie ten behoeve van mensen met communicatieve beperkingen [A round table conference on human language technology for communicatively disabled people]. Dixit, 5 (1), 11.

Cucchiarini, C., Lembrechts, D., \& Strik, H. (2008). HLT and communicative disabilities: The need for co-operation between government, industry and academia. Proceedings of LangTech-2008, Rome, 125-128.

Daelemans, W., \& Strik, H. (2002). Het Nederlands in taal- en spraaktechnologie: Prioriteiten voor basistaalvoorzieningen [Dutch put into human language technology: Priorities for a minimum common set of HLT resources]. Den Haag: Nederlandse Taalunie.

Duchateau, J., Kong, Y.O., Cleuren, L., Latacz, L., Roelens, J., Samir, A., Demuynck,, K. Ghesquière, P. Verhelst W., Van hamme, H. (2009). Developing a reading tutor: Design and evaluation of dedicated speech recognition and synthesis modules. Speech Communication, 51, 985-994.

Elenius, K., Forsbom, E., \& Megyesi, B. (2006). Language Resources and Tools for Swedish: A Survey. Proceedings LREC.

Engelter, S.T., Gostynski, M., Papa, S., Frei, M., Born, C., Ajdacic-Gross, et al. (2006). Epidemiology of Aphasia Attributable to First Ischemic Stroke. Incidence, Severity, Fluency, Etiology, and Thrombolysis. Stroke, 37, 1379-1384.

Kenis, D. (2009). Een technologische forecast in Vlaanderen over taal- en spraaktechnologie voor het Nederlands [A technological forecast on Dutch human language technology in the Flanders]. Vlaamse overheid Departement Economie, Wetenschap en Innovatie. Downloaded from http://ewi-vlaanderen.be/documenten/EWI Eindrap port TSTTechnologyForecast.pdf on July 1, 2009

Krauwer, S. (1998). ELSNET and ELRA: A common past and a common future, ELRA Newsletter, 3(2).

Maegaard, B., Krauwer, S., \& Choukri, K. (2009). $B L A R K$ for Arabic. MEDAR report.

Niewold, C. (2006). Spontaan herstel van afasie in en na de acute fase [Recovery from aphasia in and beyond the acute phase]. $\mathrm{PhD}$-thesis, University of 
Amsterdam, The Netherlands.

Rietveld, T., \& Stolte, I. (2005). Taal- en spraaktechnologie en communicatieve beperkingen. [Human language technology and communicative disabilities] Den Haag: Nederlandse Taalunie.

Strik, H. (2008). Spreekt en luistert hij al? [Does it speak and hear yet?], Dixit, 5(1), 9-10.

Van Nuffelen, G., Middag, C., De Bodt, M., \& Martens, J.P. (2009). Speech technology-based assessment of phoneme intelligibility in dysarthria. International Journal of Language \& Communication Disorders, 44, 716-730. 